\title{
Direito à cidade e violência no Brasil: considerações reflexivas
}

\section{Right to city and violence in Brazil: reflective con- siderations}

\author{
Elson Manoel Pereira*
}

Recebido: 11/09/2017. Aprovado: 23/11/2017.

Resumo: A violência no Brasil apresenta números impressionantes. Ela caracteriza-se como um fenômeno essencialmente urbano que atinge principalmente homens jovens, negros e pobres. Este artigo reflete sobre sua relação com a cidade. A cidade brasileira, no contexto de um capitalismo periférico, apresenta-se com um espaço segregado, desigualmente desenvolvido, onde as políticas públicas de promoção de direitos são igualmente desiguais e os investimentos regressivos. O artigo aponta a existência de dois circuitos da economia, um superior e outro inferior, que resulta em duas cidades desiguais, mas articuladas entre si. Essas duas cidades, dentro de uma só realidade, representam dois paradigmas: o da cidade-mercado e o da cidade-direito. No primeiro, o habitante é visto como cliente consumidor e no segundo como cidadão portador de direitos. Esta cidade segregada e desigual apresenta espaços onde a violência também se apresenta desigualmente. Por fim, o artigo apresenta o conceito de Direito à Cidade como utopia de uma cidade integrada socialmente e não violenta.

Palavras-chave: Cidade. Violência. Direito à cidade.

Abstract: The violence in Brazil has impressive numbers. It is characterized as an essentially urban phenomenon that affects mainly young, black and poor men. This article reflects on your relationship with the city; the Brazilian city, in the context of peripheral capitalism, presents itself with a segregated space, unequally developed, where public policies for the promotion of rights are equally unequal and regressive investments. The article points to the existence of two economic circuits, one superior and one superior, which results in two unequal but interconnected cities. These two cities, within a single reality, represent two paradigms: the city-market and the city-rigth. In the first, the inhabitant is seen as

* Doutor em Urbanismo e Planejamento (Institut d'Urbanisme, Grenoble, 1999). Professor dos Programas de Pós-Graduação da Universidade Federal de Santa Catarina (UFSC), Florianópolis, e de Planejamento Territorial da Universidade do Estado de Santa Catarina, Florianópolis. Pesquisador do CNPq. Professor convidado das Universidades de Grenoble (França), Montreal (Canadá) e Coimbra (Portugal).

E-mail: elsonmp@hotmail.com 
a consumer customer and in the second as a citizen with rights. This segregated and unequal city presents spaces where violence also presents unevenly. Finally, the article presents the concept of the Right to the City as a utopia of a socially integrated and non-violent city.

Keywords: City. Violence. Rigth to the city.

\section{Introdução}

A violência atinge o cotidiano da população brasileira; os estudos sobre o tema abordam os mais diversos aspectos e em muitos campos do conhecimento: Sociologia Urbana, Direito, Psicologia, Políticas Públicas etc.

A violência apresenta diversos fatores de análise, passando daqueles ligados aos indivíduos a fatores estruturais que a condicionam, ou ao menos a influenciam.

Como estudioso do fenômeno urbano, verifico que a cidade, sua forma, seus processos e sua estrutura interna guarda relação dialética com a sociedade onde está inserida. Cada sociedade cria e organiza suas cidades e por elas é influenciada: o homem constrói a sua casa e ao construí-la também se constrói. Cidades que propiciam a convivência, que respeitam a alteridade, que criam espaços que favoreçam a sociabilidade, que promovam direitos e garantem serviços básicos, contribuem para uma sociedade sem violência.

Nossa preocupação neste artigo repousa, sobretudo, nos fatores estruturais da violência e principalmente na compreensão da relação entre violência, formação da cidade capitalista e o direito à cidade.

\section{A violência no Brasil}

Os números da violência urbana no Brasil são alarmantes; o IPEA (2017)1 apresenta dados de 2015, quando quase sessenta mil pessoas foram vítimas de homicídios, numa relação de 29 mortes a cada 100 mil habitantes. Esses números tomam proporções preocupantes por si mesmos e quando comparados com outros países verificamos que a violência no Brasil tem características de uma catástrofe social: a OMS coloca o Brasil em nono lugar em mortes violentas no mundo; a América Latina é responsável por $38 \%$ e o Brasil por $10 \%$ dos assassinatos no mundo. Se somarmos as mortes decorrentes de acidentes de trânsito, chegaremos próximos do incrível

1 IPEA. Atlas da Violência. Rio de Janeiro: IPEA, 2017. 
número de 100 mil mortes por ano. Ficando apenas nesses dois indicadores, sem considerarmos a violência contra a mulher, a homofobia e outras formas de violência não menos importantes, já teríamos elementos suficientes para a defesa da necessidade de uma política pública de combate à violência, assumida como prioridade por parte do Estado brasileiro.

Quando olhamos mais de perto os números dos homicídios no Brasil, precisamos destacar alguns elementos importantes. $\mathrm{O}$ primeiro deles diz respeito à escala crescente do número de homicídios desde 2005, o que indica um combate ineficaz da violência por parte do Estado ou mesmo a inexistência de uma política pública direcionada ao combate estrutural da violência no país.

\section{Gráfico 1 - Evolução dos homicídios no Brasil}

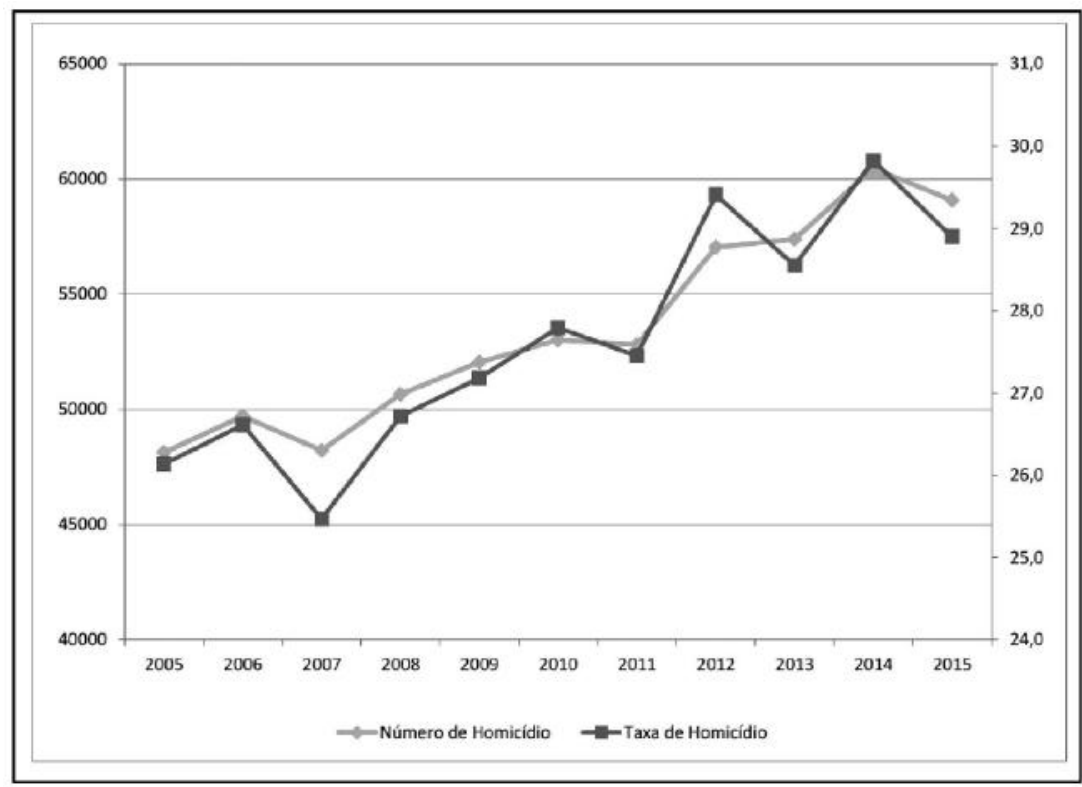

Fonte: IPEA (2017), p. 7.

Este crescimento dos homicídios, no entanto, não é homogêneo no território nacional; enquanto a região sul mostra uma estabilidade do número de homicídios, com a presença das cidades menos violentas do país, a região sudeste apresentou uma diminuição dos índices e as regiões norte e nordeste apresentaram quatro estados com crescimento dos homicídios superior a 100\% (IPEA, 2017). 
Outro dado importante trazido pelo IPEA é que os homicídios têm uma grande concentração entre os homens na faixa etária entre 15 e 29 anos: $47,8 \%$ do total de homicídios. Tão preocupante quanto à proporção, é que a morte de homens nessa faixa etária é crescente desde 2005.

Ao lado disto, cabe destacar o alto índice de mortes entre a população negra: de cada 100 mortes por homicídio no Brasil, 71 são de negros. Segundo o IPEA, um cidadão negro tem $23 \%$ mais riscos de ser assassinado que um cidadão branco. Enquanto a taxa de homicídios entre cidadãos não negros no Brasil é de cerca de $15 \%$, entre os negros é de $38 \%$.

Assim, a violência atinge, sobretudo, homens, jovens, negros e com baixa escolaridade. Segundo Silva,

os homicídios são causados por fatores individuais e estruturais, que se encontram intimamente relacionados. Os fatores individuais referem-se aos perfis sociobiográficos de vítimas e acusados, enquanto os fatores estruturais denotam o contexto sociodemográfico e territorial, características urbanas e sociais nas quais os indivíduos estão inseridos. ${ }^{2}$

Que elementos estruturais seriam esses? Segundo Cerqueira, Lobão e Carvalho (2005) $)^{3}$, poderíamos citar pelo menos questões relacionadas às vulnerabilidades e desigualdades socioeconômicas e a falência do Sistema de Justiça Criminal, que teriam facilitado o crime organizado. Esses autores apontam os seguintes elementos explicativos da criminalidade no Brasil:

- o crescimento da população urbana no país, que levou a demandas por políticas públicas não respondidas pelo Estado;

- a exclusão conjugada à desigualdade econômica, que potencializam desajustes sociais;

- a proliferação e o uso indiscriminado das armas de fogo pela população;

- a ineficácia do Sistema de Justiça Criminal;

- e a ausência histórica de uma Política de Segurança Pública.

Embora saibamos que não haja relação causal entre condições sociais e violência, entendemos que espaços de pobreza, de ausência de direitos civis, sociais e econômicos estão associados a espaços que expõem as pessoas à violência. As populações empobrecidas são as primeiras vítimas da violência:

2 RAMÃO, F. e WADI, Y. Espaço urbano e criminalidade violenta: análise da distribuição espacial dos homicídios no município de Cascavel/PR. Rev. Sociol. Polít., Curitiba, v. 18, n. 35, p. 207-230, fev. 2010, p.217.

3 Apud RAMÃO, F. e WADI (2010). 
os registros de homicídios revelam que os cenários mais recorrentes são os bairros que compõem a periferia urbana, onde as condições sociais de existência coletiva são precárias e a qualidade de vida encontra-se degradada. Assim, a combinação entre múltiplas carências econômico-sociais soma-se a graves violações dos direitos humanos, criando um contexto propício para que a violência prospere. Nessas áreas, os governos municipais e estaduais pouco têm feito para prover seus moradores de meios adequados à existência digna. Os autores acreditam que, no Brasil, o crescimento da violência nas áreas urbanas não possa ser compreendido adequadamente se o abismo que caracteriza o acesso aos direitos econômicos e sociais, para amplas parcelas da população, não for considerado. ${ }^{4}$

\section{A cidade brasileira}

A cidade brasileira é fundamentalmente desigual, fruto da modernização incompleta da sociedade brasileira; seus espaços de pobreza não são residuais ou de subdesenvolvimento de algumas áreas em relação a outras do território: eles são estruturalmente produzidos. Milton Santos (1979), geógrafo brasileiro, ao analisar a urbanização dos países da América Latina, identifica a existência de dois circuitos da economia que produzem e ao mesmo tempo são produzidos pela cidade do capitalismo dos países periféricos; uma segmentação que cria diferenças quantitativas e qualitativas no consumo. Essa realidade das economias das cidades da periferia do capitalismo seria, então, a causa e o efeito da existência:

- de um circuito superior, que constitui o resultado direto das modernizações que atingem o território. Ele é representado por uma cidade formal regulada por planos e que acompanha e participa da aceleração contemporânea global. Nesta cidade temos habitações de bom nível, escolas, serviços públicos, sistemas de segurança pública etc.

- e um circuito inferior da economia, articulado ao primeiro, mas composto pelas formas de fabricação do capital não intensivo, de serviços não modernos e o pequeno comércio do varejo, voltados, sobretudo ao consumo da população pobre. Esse circuito constitui uma cidade informal fora das leis urbanísticas e dos direitos fundamentais, localizada onde as leis proíbem a ocupação: morros, manguezais, dunas, áreas alagáveis próximas a rios etc.

4 CARDIA, ADORNO e POLETO (2003), apud RAMÃO e WADI, 2010, p. 218. 
O efeito espacial mais visível desses dois circuitos da economia é a segregação urbana, que se traduz fundamentalmente de duas formas: a segregação imposta às populações de baixa renda que, por não terem acesso ao mercado imobiliário formal, são levadas a ocupar áreas proibidas pelas leis ambientais ou urbanísticas. Em muitas cidades brasileiras essas áreas correspondem a mais de 30\% de seu território. A segunda forma seria a de autossegregação das classes média e rica, que se isolam em subespaços do território municipal de forma a criarem territórios privilegiados de vida; eles se traduzem principalmente em condomínios residenciais fechados, mas igualmente em espaços de consumo exclusivos como em shoppings centers ou mesmo de espaços privados que reproduzem espaços públicos, mas sem qualquer respeito à alteridade.

Nos espaços segregados, ocupados pela população pobre, do circuito inferior da economia, há menos investimentos públicos, menos direitos garantidos pelo Estado e, por vezes, total ausência do Estado. Por outro lado, os lugares ligados ao circuito superior da economia, mesmo já possuindo muita infraestrutura urbana, recebem especial atenção do poder público, recebendo ainda mais investimentos, num processo que chamamos de investimentos regressivos.

A estrutura de uma cidade segregada tem relação direta com a dinâmica da cidade; os espaços públicos, por exemplo, são evitados pelas classes média e rica; desta forma, a cidade, ao invés de um lugar de encontro e convivência, é antes de tudo um lugar de passagem, um lugar a ser evitado. Encontramos mesmo um fenômeno que alguns autores denominam de Agorafobia Urbana. O espaço público que deveria ser o espaço da alteridade, de compartilhamento, de encontros não programados, de sociabilidade, se transformou no Brasil no lugar do medo da violência, do evitamento, como se o outro, o desconhecido, o pertencente a outra classe social, fosse um potencial portador de violência. E o círculo vicioso está criado: as pessoas evitam frequentar o espaço público (praças, ruas, esquinas) e quanto menos pessoas frequentam esses espaços, menos seguros se apresentam e menos pessoas o frequentam:

Este indivíduo condominizado não se direciona para o espaço público praças, ruas, vizinhos, uma vez que se encontra assentado em solitárias formas de convivência. Do Outro, visto como ameaçador ou como uma cópia imperfeita do Eu, é preciso se afastar, uma vez que o diferente deve ser banido de sua convivência. ${ }^{5}$

Esta cidade do capitalismo periférico reflete não apenas a lógica do capital em geral, mas cada fase particular em que esse sistema se

5 VILHENA, Junia de. Da claustrofobia à agorafobia. Cidade, confinamento e subjetividade. Revista Rio de Janeiro, n. 9, p. 77-90, jan./abr. 2003, p. 86. 
encontra; a cada fase do capitalismo, a cidade responde com políticas urbanas específicas. Para Harvey (2012), "a urbanização sempre foi um fenomeno de classe, já que o excedente é extraído de algum lugar e de alguém, enquanto o controle sobre a distribuição repousa em umas poucas mãos". Para o autor, na fase do capitalismo atual, a "expansão do processo urbano trouxe com ela incriveis transformações no estilo de vida". ${ }^{7} \mathrm{Na}$ fase atual de financeirização do capital onde a produção mundial (que produz empregos) é escandalosamente menor que o capital financeiro puramente especulativo, a própria cidade tornou-se mercadoria.

No entanto, o binômio modelo de desenvolvimento-modelo urbano não acontece sem reações, sem resistências. Como aponta Orlando Santos Jr. (2007), assistimos hoje nas cidades brasileiras a uma clara disputa entre aqueles que as querem como espaço de vida, colocando em relevo seu valor de uso, e aqueles que as querem como mercadoria e que se utilizam das políticas e os recursos públicos para preparar as cidades para receber o excedente do capital; seriam dois modelos de cidade em disputa: a CidadeMercado e a Cidade-Direito. A primeira poderia ser assim definida:

a política urbana é transformada em relações de mercado, nas quais ganha quem tem maior poder os lucros e os custos da ação do Poder Público [...]. No nivel do planejamento esse paradigma busca sua legitimação por meio de estratégias discursivas fundadas nos modelos do planejamento estratégico, em experiências bem sucedidas e na referência de cidades-modelos, difundidas pela ação de atores hegemônicos que articulam agências multilaterais, capitais financeiros, governos nacionais e locais. ${ }^{8}$

O paradigma da cidade-mercado alinha a política urbana à política de desenvolvimento do estágio do capitalismo em nível mundial, não obstante as especificidades locais.

O segundo modelo, o paradigma da cidade-direito, estaria, segundo o autor, ainda em construção, e

afirma o papel central do poder público no planejamento urbano e o seu compromisso com o enfrentamento dos mecanismos de produção de desigualdades e exclusão decorrentes da vigência da dinâmica do mercado no uso e ocupação do solo urbano e do controle do poder político pelos históricos interesses patrimonialistas. ${ }^{9}$

\footnotetext{
HARVEY, p. 74.

HARVEY, 2012, p. 84.

8 SANTOS JR., 2007, p. 306.

9 SANTOS JR., 2007, p. 307.
} 
Os dois paradigmas olham para a cidade, evidentemente, de maneira não apenas diferente, mas conflitante. A cidade é por isto um território em disputa não apenas entre os diferentes capitais, mas igualmente entre os capitais e aqueles que vêem o território da cidade como lugar de direitos.

\section{Um duplo grito pelo direito à cidade}

Em 1968, ao analisar as soluções habitacionais propostas pelo Estado francês diante do déficit habitacional de dois milhões de moradia do pós-guerra, Henry Lefebvre ${ }^{10}$ faz profunda crítica aos grandes conjuntos habitacionais construídos na periferia de Paris, segundo a lógica da estandardização da moradia, funcionalização e separação da função habitar do direito à inserção urbana. Para o autor, a prática social deveria ser integrativa, o urbanismo, como campo de conhecimento responsável de pensar e agir sobre a cidade, poderia muito bem se tornar essencial para esta prática integrativa. No entanto, a cidade capitalista ao mesmo tempo em que pratica a segregação, igualmente projeta a separação na prática.

Para Lefevre,

"habitar era participar de uma vida social, de uma comunidade, aldeia ou cidade. A vida urbana detinha, entre outras, essa qualidade, esse atributo. Ela deixava habitar, permitia que os citadinos-cidadãos habitassem"."

No entanto, se a condição de proletário geralmente garantiu no contexto francês um abrigo, as possibilidades concretas oferecidas em termos de moradia eram muito reduzidas: subúrbios, vilas operárias oumais tarde, os grandes conjuntos residenciais. A questão do Habitar foi prejudicada por uma geração de ações urbanísticas de forma essencialmente quantitativa, avaliadas em função do número de moradias disponibilizadas, e através das quais parece monumentalizado a moradia, isto em detrimento de lugares e construções mais comunitários, ou até mesmo públicos ${ }^{12}$.

E quando finalmente foi conseguido resolver o problema de falta de habitação e de condições sanitárias, Henri Lefebvre demonstra os limites da reflexão centrada, antes de tudo, na questão da moradia. O sociólogo e geógrafo francês vem neste momento sublinhar a questão do habitar; sua

10 LEFEBVRE, H. O Direito à Cidade, Paris, 1968.

11 LEFEBVRE, 1968, p. 18.

12 PINSON, D. La monumentalisation du logement: l'architecture des ZUP comme culture. Les annales de la recherche architecturale. 1997. 
crítica às soluções dadas ao problema habitacional francês dizia respeito à impossibilidade de as populações atendidas terem o direito de viverem a cidade. Longe da cidade, elas tinham apenas o direito de visitarem a cidade. No nível ecológico, o habitar torna-se essencial. A cidade envolve o habitar; ela é forma, envelope desse local de vida "privada", ponto de partida e de chegada das redes que permitem as informações e que transmitem as ordens próxima e distante.

$O$ Direito à Cidade significa, socialmente, o encontro e a reunião daquilo que existe nos arredores, na vizinhança (bens e produtos, atos e atividades, riquezas) e, por conseguinte, a sociedade urbana como lugar socialmente privilegiado, como sentido das atividades (produtivas e consumidoras), como encontro da obra e do produto. O Direito à Cidade está ligado à criação de uma vida alternativa urbana menos alienada, que promova a emancipação humana.

O Direito à Cidade se configura como um duplo grito: uma exigência, uma demanda às necessidades de reprodução social na cidade; direito à habitação, à saúde, à serviços públicos, ao saneamento ambiental etc. No entanto, esses direitos fundamentais devem ser demandados a partir de um projeto coletivo por uma nova cidade, expressando o direito de reivindicar algo que ainda não existe, o direito a uma outra cidade, menos segregada, mais integrativa, promotora de sociabilidade onde o outro, antes de uma ameaça, é alguém a ser respeitado e com quem sou convidado a conviver.

O Direito à Cidade está ligado à criação de uma vida alternativa urbana menos alienada, que promova a emancipação humana. Trata-se do direito de reconstruir a cidade na perspectiva da justiça social e da felicidade.

\section{Considerações conclusivas}

A violência no Brasil tem aspectos individuais e estruturais; entre esses últimos encontram-se os aspectos espaciais. O território urbano, no contexto brasileiro, apresenta-se desigualmente desenvolvido e produz espacialidades que materializam de um lado uma cidade formal, com leis urbanísticas estabelecidas, com serviços modernos e de outro, uma cidade que exclui e priva sua população dos mínimos elementos para a reprodução da vida. A cidade brasileira é estruturalmente segregada; sua forma e sua dinâmica testemunham isto. Longe de promover a convivência de diferentes e a integração social, ela promove a criação de lugares de "iguais" que se separam dos "diferentes". Lugares segregados em relação à moradia, mas também relacionados ao consumo, ao estudo e ao lazer. As políticas públicas não combatem essa segregação; ao contrário, chegam mesmo a 
produzi-la, como no caso do programa habitacional Minha Casa Minha Vida, que destina as franjas da periferia urbana aos mais pobres.

Os investimentos públicos são regressivos, alimentando a exclusão social e os ganhos imobiliários privados; as áreas da cidade já providas de infraestrutura recebem ainda mais investimentos, enquanto as áreas empobrecidas, desprovidas de saneamento, energia, serviços de transporte coletivo e outros serviços, nada ou pouco recebem.

Henry Lefebvre desenvolve o conceito de Direito à Cidade apresentando-o como um duplo grito: uma exigência por direitos fundamentais como moradia, educação, saneamento e uma demanda por outro tipo de cidade, mais integrada, menos violenta. O Direito à Cidade exige a construção de novas formas urbanas, de novas estruturas sócio-espaciais que favoreçam a integração e o respeito à alteridade. Isto poderá se constituir nas bases de uma sociedade menos violenta.

\section{Referências}

BRASIL tem nona maior taxa de homicídios do mundo, diz OMS. O Estado de São Paulo, 17 mai. 2017. Disponível em: <http://brasil. estadao.com.br/noticias/geral,brasil-tem-9-maior-taxa-de-homicidios-do-mundo,70001788030>.

HARVEY, D. O Direito à Cidade. Lutas Sociais, São Paulo, n.29, p.7389, jul./dez. 2012.

IPEA. Atlas da Violência. Rio de Janeiro: IPEA, 2017.

LEFEBVRE, H. Le droit à la ville. Anthropos : Paris, 1968.

PINSON, D. La monumentalisation du logement: 1'architecture des ZUP comme culture. Les annales de la recherche architecturale. 1997.

RAMÃO, F. e WADI, Y. Espaço urbano e criminalidade violenta: análise da distribuição espacial dos homicídios no município de Cascavel/PR. Rev. Sociol. Polit., Curitiba, v. 18, n. 35, p. 207-230, fev. 2010.

SANTOS JR., O. Cidade, cidadania e planejamento urbano: desafios na perspectivada reforma urbana. In: FELDMANN, S. et FERNANDES, A. (orgs). O Urbano e o Regional no Brasil contemporâneo: mutações, tensões, desafios. Salvador: EDUFBA, 2007. P. 293-314.

SANTOS, M. O Espaço Dividido: os dois Circuitos da Economia Urbana nos Países subdesenvolvidos. Tradução de Myrna T. Rego Viana. Rio de Janeiro: F. Alves, 1979.

VILHENA, Junia de. Da claustrofobia à agorafobia. Cidade, confinamento e subjetividade. Revista Rio de Janeiro, n. 9, p. 77-90, jan./abr. 2003. 